\title{
¿Presencia de Ireneo en el Comentario al Cantar de Gregorio de Nisa?
}

\author{
ALEJANDRO E. NiCOLA \\ Pontificia Universidad Católica de Chile (Chile) \\ alejandroenriquenicola@yahoo.com.ar
}

\begin{abstract}
Resumen
El presente artículo trata de mostrar la presencia del pensamiento de Ireneo de Lyon en el sustrato del pensamiento de Gregorio de Nisa en una de sus obras cumbres: el Comentario al Cantar de los Cantares. Esta obra refleja la confluencia de una profunda reflexión a partir del texto bíblico y la filosofía de la época. El niseno se ubica en la tradición de los autores eclesiásticos que han comentado este bello poema de amor veterotestamentario. Si bien es cierto que en la edición crítica de la obra no aparece nunca citado el lugdunense se pueden encontrar ciertos núcleos conceptuales y temáticos que ayudan a descubrir una recepción de Ireneo en el Comentario al Cantar de Gregorio. Esos elementos permiten poner de relevancia la relación existente entre estos dos autores patrísticos que se conectan para mostrar la realidad esponsal de la iglesia que posee un dinamismo pneumático-salvífico abierto a toda la humanidad.
\end{abstract}

Palabras claves: Gregorio de Nisa, Ireneo de Lyon, Comentario al Cantar de los Cantares, eclesiología, pneumatología.

\section{Presence of Irenaeus in the \\ Commentary on the Song of Gregory of Nyssa?}

\begin{abstract}
The purpose of this article is to show how Ireneus of Lyon's thought was present in one of Gregory of Nyssa's fundamental works: Commentary on The Song of Songs. This work reflects a convergence of deep biblical reflection and the philoshophy of the time. Gregory is among the ecclesiastical writers who have commented on this beautiful love poem in the Old Testament. Even though there is no mention of the Lugdunian in the critical edition of the work, some concepts and themes may be found which belp identify an influence form Ireneus on Gregory's Commentary on the Song of Songs. These elements allow us to give relevance to the relationship between these two patristic authors, who come into contact in order to show the church's spousal reality, which has a pneumatological-salvific dynamics, open to all mankind.
\end{abstract}

Key words: Gregory of Nyssa, Irenaeus of Lyon, Commentary on the Song of Songs, body, ecclesiology, pneumatology.

Sacerdote de la Arquidiócesis de Córdoba, Argentina. Magister en Teología Patrística por la Pontificia Universidad Católica de Chile. Profesor de Teología, Historia de la Iglesia y Patrología en el Instituto Teológico de Córdoba (ITEC). Doctorando en Teología en la Pontificia Universidad Católica de Chile. Entre sus últimas publicaciones cabe mencionar los artículos "La dimensión pneumatológica de la Iglesia según Ireneo" (2013), "La exégesis de la realidad social en los Padres de la Iglesia" (2013). 


\section{Introducción}

En el prólogo al Comentario sobre el Cantar de los Cantares Gregorio de Nisa señala que existe un camino verdadero a través del lenguaje simbólico, alegorías y metáforas, para alcanzar al más alto nivel de vida del alma a través de la contemplación. Por otra parte indica cómo desde la letra se debe alcanzar el sentido espiritual escondido en la materialidad de lo escrito. Esta afirmaciones han hecho lugar a largos estudios sobre la experiencia y el lenguaje místico-religioso (Harl, 1977; Canévet, 1983; Bonato, 2005; Curzel, 2011) y el método (Gargano, 1981; Simonetti, 1985; Drobner, 2002) utilizado por el niseno hasta el punto de denominarlo «el fundador de la teología mística» en el s. IV (Daniélou, 1944).

La confluencia del dato bíblico, de las distintas corrientes de pensamiento filosófico y el manejo de las tradiciones eclesiásticas de la época han hecho difícil una delimitación de su pensamiento en una sola línea.

El sentido lírico, alegórico y sagrado del Cantar ha sido defendido desde el rabino Aquiba (en el 135) hasta la sinagoga de nuestros días. La tradición rabínica judía y autores cristianos de la antigüedad como Hipólito de Roma y Orígenes han demostrado distintos intereses por la exégesis de este poema. A partir de la obra de Gregorio habrá un influjo en todos los autores posteriores que se dediquen a la mística de este libro del Antiguo Testamento: Gregorio Magno, Pseudo-Dionisio, Máximo, Bernardo, Guillermo de Saint Thierry, Gregorio Palamas y Juan de la Cruz.

En una clara línea de continuidad con la tradición el niseno realizará su exégesis con una clara libertad frente a sus antecesores. Es posible intentar descubrir en sus escritos elementos de los grandes pensadores patrísticos previos a él. Orígenes aparece expresamente citado y comentado": «Se recoge en este libro mucho de lo que escribió Orígenes, pero yo también pongo de buen grado por escrito el fruto de mi trabajo» (In Cant. Prol., 13) ${ }^{2}$. Y también parece poder rastrearse en sus escritos una reminiscencia positiva del pensamiento de Ireneo de Lyon.

Daniélou (1964) ha expresado que en el pensamiento del niseno «se encuentran y son sintetizadas las corrientes del cristianismo antiguo: el optimismo de Ireneo de impronta estoica y el pesimismo de Orígenes de derivación platónica». Por otra parte, Gorce (1953) ha afirmado que

1 Es el autor patrístico más citado en la edición crítica (Langerbeck, 1986).

2 La obra Comentario al Cantar de los Cantares de Gregorio de Nisa se citará In Cant. seguido del número de homilía correspondiente y el número de página de la edición crítica de Langerbeck (1986). Tendremos presente el resto de las ediciones (Mc Cambley, 1987; Bouchet \& Devailly, 1992; Martín, 1993; Dünzl, 1994; Moreschini, 1996). Las traducciones al castellano serán propias. 
Gregorio suscribe el pesimismo de los místicos sobre las realidades carnales y temporales que impiden la contemplación, no está muy lejos de la dicotomía de los filósofos pero que para iluminar esa problemática se sirve del concepto de salvación de la naturaleza humana total y del valor del cuerpo en la economía proveniente de Ireneo. Van Parys (1969) apunta que M. Haarl ha señalado la necesidad de explorar más profundamente la inserción de Gregorio en la tradición eclesiástica y sus relaciones con Basilio, Atanasio, Marcelo de Ancira, Orígenes e Ireneo. Gargano (1981) hace hincapié que Gregorio ha recibido del obispo de Lyon la unidad indisoluble del Antiguo y del Nuevo testamento y de la vida de la iglesia. Recibe del lionés una verdadera y propia síntesis de la vida cristiana dada por la revelación de la sabiduría divina marcada en el tiempo de las diversas economías.

Es un hecho significativo que en la edición crítica del In Canticum de Langerbeck no aparezca nunca citado Ireneo. En las traducciones conocidas aparece en las notas seis veces en el texto francés (Bouchet \& Devailly, 1992) ${ }^{3}$, y tres veces en la edición alemana (Dünzl, 1994) ${ }^{4}$.

Entonces: ¿Hay realmente una influencia ireneana en el texto gregoriano del Comentario al Cantar? ¿Qué recoge principalmente Gregorio del santo lionés? ¿En qué medida podemos encontrar rastros del pensamiento de San Ireneo en esta obra de la etapa final del niseno?

A pesar de no encontrar citas textuales del lugdunense en la editio critica (Langerbeck, 1986) que nos ayuden a demostrar la presencia explícita de este autor pensamos que sería posible plantear la hipótesis de una presencia implícita de algunos núcleos conceptuales que descubramos subyacentes en el pensamiento de San Gregorio. De allí, podríamos deducir que ellos le permiten entroncarse en la más genuina tradición cató-

3 «...la economía como un tema querido por Ireneo (p.33); «... señala la libertad del hombre como Ireneo (p.66); «...todo el hombre entero, no solo el alma y todos los hombres son pecadores, la oveja perdida que vuelve al redil es toda la humanidad» (p.69); «...afirmación de la salud universal como Ireneo y Clemente alejandrino» (p.110); «...referencia a la cinta escarlata de Rahab como signo de la pasión de Cristo junto con la carta de Clemente y Justino e Ireneo» (p.169); «...junto con Ireneo y Orígenes, Gregorio se suma a la tradición patrística que ve en la parábola del buen samaritano la historia de la salvación resumidamente» (p.287).

4 «...controversia en torno a la teoría de la redención física, la interpretación que se da allí de la oveja perdida tiene una historia que se remonta a Orígenes, Ireneo y la variante de la Gnosis» (p.186); "...la encarnación es representada a como un autooscurecimiento del Logo en favor del pueblo. La sombra como una metáfora de la belleza de Cristo ya se encuentra en Ireneo en relación con Lam 4, 20» (p.258); «...hace referencia a la parábola del buen samaritano como resumen de la historia de la salvación, en una larga tradición donde Ireneo y Orígenes son referentes» (p.760). 
lica sin repetirla sino realizando un progreso y profundización en la historia del dogma.

En el presente trabajo nos proponemos encontrar dichos núcleos conceptuales que nos ayuden a observar algún tipo de recepción de Ireneo en el Comentario al Cantar de Gregorio de Nisa.

\section{La economía salvífica: marco teológico y fin soteriológico}

La dimensión soteriológica del concepto niseno de economía es el punto de partida de su pensamiento: «mientras que su aspecto creado (el de Cristo) consiste en haberse configurado al cuerpo de nuestra bumildad según la economía seguida para nuestro bien» (In Cant., XIII, 381). La idea gregoriana de economía tiene que ver con el plan de Dios preanunciado de antemano. El Verbo se ha manifestado en las distintas etapas de la historia de la salvación:

...mientras la esposa está dentro guardando la casa su esposo le habla por la ventana, pues un muro los separa (...) La ventana son los profetas, los cuales han entrado en la luz, mientras las rejas son la trama de los preceptos de la ley; a través de uno y otro pondrá al interior de la casa el rayo de luz verdadera (In Cant., V, 140,145).

La esposa ha ido comprendiendo el misterio escondido y tiene un vivo deseo que se manifieste plenamente su esposo en la carne: «desea ver a Dios en la carne, que el Verbo se haga carne y Dios se manifieste en la carne» (In Cant., V, 164). Así llega la plenitud económica con la epifanía de Dios en la carne «viviendo nuestra vida» y «cumpliendo con la promesa realizada» (In Cant., V, 140). Esta idea de la economía tiene un carácter pedagógico y paradójico, muestra pero a la vez esconde: «la naturaleza bumana que tú eres se ba hecho sombra por la economia (...) porque quién habría soportado (el brillo) tu manifestación y seguir viviendo?» (In Cant., IV, 107).

La referencia a la economía salvífica funciona como un marco en el pensamiento del niseno. Heredero de la reflexión eclesiástica en ese sentido no se sale del concepto del designio bondadoso de Dios con el cual ha querido manifestarse de una manera cercana y tangible al hombre. El horizonte económico permite una conexión con la más auténtica tradición cristiana. La revelación veterotestamentaria alcanza su plenitud en la encarnación del Verbo permitiendo así establecer una continuidad pero también un progreso significativo en distintas manifestaciones acontecidas. 
En ese sentido podemos decir que Gregorio de Nisa se entronca en la concepción ireneana de Historia salutis: «existe un único y mismo Dios que desde el inicio hasta el fin de la bistoria, a través de distintas disposiciones, ha acompañado al género humano» (Adv. Haer., III, 12, 13) ${ }^{5}$. Este es el horizonte en el que se enclava todo el pensamiento del lugdunense (Adv. Haer., I, 10,3; III, 16,6; III, 24,1). Para Ireneo todo gira en torno a la salvación del hombre entero, desde su creación hasta su madurez como hombre pleno. El obispo de Lyon se destaca por plantear siempre su pensamiento a partir del concepto de «disposición» o «economía» a lo largo de la historia de la salvación de la humanidad. Este concepto se convierte en un punto central de su teología: es una noción organizadora desde un diseño donado. Como dice Fantino (1994: 93), es la acción productiva, el término de la acción: la obra; la disposición, el acuerdo, el diseño.

\section{La encarnación: el brillo de la gloria en la carne}

En la epifanía económica del Verbo en la carne brilla la gloria. Para el niseno la Gloria es el Espíritu Santo:

...que el Espíritu Santo sea llamado gloria, ninguna persona prudente se negaría a decirlo así, teniendo en cuenta las palabras del Señor que dice: «yo les he dado la gloria que tú me diste». En realidad les dio la misma gloria a los discípulos cuando dijo: «Reciban el Espíritu Santo». Esta gloria que tuvo siempre, antes de que el mundo existiese, la recibió cuando tomó la naturaleza humana. Glorificada por el Espíritu Santo, todo lo que tenga relación con la gloria participa del Espíritu Santo a partir de los apóstoles (In Cant., XV, 467).

Por lo tanto la carne se ha vuelto brillante por la donación que el Padre ha hecho al Hijo a partir del momento de la encarnación:

...si tú no te hubieras hecho hombre velando los rayos inmaculados de tu divinidad con tu forma de esclavo quien habrá soportado tu manifesta-

\footnotetext{
5 La obra Contra los Herejes de Ireneo será citada como Adv. Haer. indicando el libro, el capítulo y parágrafo. En lo que respecta al texto nos basaremos en la última edición crítica (Rousseau, Hemmerdinger, Doutreleau \& Mercier, 1965/1969; Rousseau \& Doutreleau, 1974/1979/1982). Sin embargo, tendremos presente el resto de las ediciones (Sagnard, 1952; Brox, 1995; Orbe, 1985-1996). Las traducciones al castellano serán propias. En lo que respecta a la Demostración de la Predicación Apostólica-Epideixis- hemos utilizado la traducción de Posse (1992), allí usaremos la siguiente abreviatura: Epid. seguido del número de capítulo.
} 
ción? (...) has venido con los rayos fulgurantes de tu divinidad velados por tu cuerpo (In Cant., IV, 108).

El esposo, Cristo, oculta el esplendor de su divinidad en la naturaleza material de su cuerpo humano al aparecer en la economía. Manifiesta un carácter de sombra que se percibe como intermediario entre las tinieblas y la luz. De esta forma esta característica adquiere la categoría de misterio en cuanto que es la comunión de la naturaleza humana con el ser divino y permite también entender la unión entre Cristo y la Iglesia.

La impasibilidad ( $\alpha \dot{\alpha} \theta \varepsilon \varepsilon \alpha)$ aparece como acción del Espíritu que actúa sobre la carne-cuerpo desafectado la negatividad y transformándola en vida espiritual que lleva a la integración y a la unidad: «El carácter de impasibilidad que la hace hermana de los espirituales ha llevado a feliz término la impasibilidad de su carne» (In Cant., VIII, 254). No aparece en el sentido de la negación de las pasiones sino como su transformación (In Cant., V, 140; XV, 466-68).

Con la encarnación Dios se manifiesta, en la carne se hace epifanía. Este es un misterio: una auténtica mezcla, mixtura ( $\left.\sigma v \nu \alpha \nu \alpha_{i} \kappa \rho \alpha \sigma \varepsilon \omega \varsigma\right)$ (In Cant., V, 145) entre lo divino y lo humano; no en cuanto se pierda la identidad de cada una, sino que se da un contacto íntimo entre ellas. Hay en el ser una presencia trascendente absoluta de Dios y una inmanencia fundamental. Se da un punto de contacto, entre el Ser del Creador y el ser de la criatura. Ese contacto es la perfecta realización del amor. Podemos afirmar que se trata de un verdadero contacto ontológico (Nicola, 2009: 456-7). Esto le permite a Dios asumir un rostro concreto, se hace visible, puede ser contemplado. De esa manera los que contemplan se pueden convertir en el objeto contemplado. Así el cuerpo se convierte en mediador e instrumento de la divinidad.

Y por la acción del Espíritu Santo todas las partes se hacen un solo cuerpo por el vínculo de la paz y la misma esperanza (In Cant., XV, 466468). Esta unidad no destruye la diversidad ni la singularidad sino que al contrario permite mirar más ampliamente el conjunto. El recurso a la cita joanea en el tramo final del Comentario al Cantar: «que sean uno como túy yo..., para eso les di mi gloria» explicita la dimensión trinitaria que ha estado atravesando todo el texto del niseno. La gloria es el testimonio visible del misterio trinitario que es uno y distinto, resolviéndose así la tensión entre el todo y la parte. El vínculo unificante del amor trinitario entre los miembros es posible porque ha habido diferencias. Los contarios de la paradoja se pueden encontrar en un lugar común: un cuerpo continente de la divinidad. La gloria del Espíritu Santo se lleva consigo a todos los que son connaturales a él. Esa connaturalidad se fue dando en un proceso de glorificación del cuerpo por la acción del Espíritu. 
Para Ireneo de Lyon la carne de Cristo es el continente del Espíritu. Cristo recapitula en sí mismo a todos los hombres (Sesboüé, 2000: 70-71; Polanco, 2010: 159-191). La humanidad es tocada por el Espíritu divino que se acostumbra a morar en el género humano. Ireneo al decir que el Espíritu se acostumbra a reposar en los hombres está afirmando una permanencia a través de un verbo de contacto:

Por eso también descendió sobre el Hijo de Dios hecho Hijo del Hombre, para acostumbrarse a habitar con él en el género humano, a descansar en los hombres y a morar en la criatura de Dios, obrando en ellos la voluntad del Padre y renovándolos de hombre viejo a nuevo en Cristo (Adv. Haer., III, 17,1).

Las imágenes de contacto entre realidades distintas, son muy queridas para Ireneo. Entre ellas existe una clara relación que manifiesta un vínculo entre estas distintas imágenes que también indican cierta caracterización y progreso ${ }^{6}$. Estas expresiones en su mayoría parecen expresar el amor de los esposos. De allí que pensamos que la noción de comunión ireneana tiene que ver con un abrazo que el Espíritu, una de las manos ${ }^{7}$ de Dios, hace a la carne y que por lo tanto posee un marcado matiz esponsal. No es una categoría mental la que se piensa al modo de una metáfora sino que se está señalando una verdadera unión metafísica.

6 Pueden verse (Nicola, 2013: 10-11), por ejemplo: a) Comunión (communio): comunión, asociación, sociedad, comunidad, comunicación, participación mutua: Spiritus Dei habitat in vobis, hoc autem non secundum jacturam carnis sed secundum communionem Spiritus fit... (Adv. Haer., V, 8,1); et esse eum qui sit talis non jam carnales, sed spiritalem, propter Spiritus communionem (Adv. Haer., V, 9,2); ...propter Spiritus communionem... (Adv. Haer., V, 11,1). b) Tomar esposo (assumo): tomar a su cargo para sí, añadir a lo que se tiene o posee, usado en el Derecho Romano, el varón poseía a la mujer: Sicut igitur sponsa assumere sponsum non potest, asumi autem a sponso potes (Adv. Haer., V, 9,4). c) Rodear por dentro y por fuera (circumdo): Spiritus autem circumdans intus et foris hominen... (Adv. Haer., V, 12,2). Este fue el vocablo latino que tradujo el griego $\pi \varepsilon \rho \iota \lambda \alpha \beta$ óv, que significa rodear con los brazos, cercar. Así aparece en la cita del Fragmento griego que se conserva. Orbe (1985) observa que este término no ha sido usado en el Nuevo Testamento ni en los Padres Apostólicos, y que en el Antiguo Testamento en Cant 2, 6 sugiere el abrazo carnal, y en Sir 30, 20 este abrazo aparece como ilícito. d) Abrazar (complector): envolver, cercar, rodear, enlazar, apoderarse, abrazar, estrechar con los brazos: ...pignus complectens hominem in semetipsum... (Adv. Haer., V, 8,1);...Spiritus complectitur carnem... (Adv. Haer., V, 13,4). e) Deleitar (delecto): atraer, retener, deleitar, producir placer, agradar, complacer, seducir: ...mundum templum esse vult, ut delectetur Spiritus Dei in eo, quemadmodum sponsus ad sponsam (Adv. Haer., V, 9,4).

Las «manos de Dios» es una expresión típica y muy querida en el vocabulario del Obispo de Lyon para hacer referencia al Hijo y al Espíritu Santo (Verbo y Sabiduría). Véase, Adv. Haer., IV, pref, 4; 20,1; V, 1,3; 5,1; 6,1; 28,4; Epid.11 entre otros. Se convierten así en instrumento divino: per manus. 
El Espíritu abraza la carne transfigurándola. El obispo de Lyon utiliza en Adv. Haer., V,8,1 complectens hominen (Orbe, (1985: 375.642-643) para expresar la idea de un abrazo iniciado pero no consumado, como el esposo atrae a sí y abraza a su esposa y se deleita en esa acción tomando la iniciativa:

Por eso quiere que nuestra carne sea templo puro, para que el Espíritu de Dios se deleite en él, como el esposo en la esposa. Pues así como la esposa no puede desposar al esposo, pero sí puede ser desposada por el esposo cuando éste viniere a acogerla, de modo semejante esta carne por sí misma, o sea ella sola, no puede poseer en herencia el Reino de Dios. Pues el que vive recibe en herencia las cosas que eran del que ha muerto; y una cosa es el que posee en herencia, y otra la que es poseída en herencia: el primero domina y dispone y gobierna lo que posee en herencia, a la manera como quiere; en cambio, las cosas poseídas están sujetas, obedecen y están subordinadas a aquél, y existen bajo el dominio del que las posee ( $A d v$. Haer. V, 9,4).

La carne transfigurada de Cristo resucitado se convierte en paradigma de lo que le sucederá a la carne de los justos en el tiempo final con la invasión del Espíritu del Padre: «se transfigura, porque mortal y corruptible como es, se vuelve inmortal e incorruptible» (Adv. Haer., V, 13,3). El lugdunense confirma el carácter unitivo del Espíritu con la carne a través de la imagen del abrazo: Spiritus complectitur carnem, otorgando así a los justos la capacidad de recibir la vida plena en la resurrección (Adv. Haer., V, 13,4).

La carne glorificada del Verbo es el modelo final de todo. La humanidad gloriosa de Jesús ha alcanzado su máximo esplendor. De esta manera se entiende que la gloria del Padre por el Espíritu se irradie portentosamente en la carne del Salvador: "De suerte que la luz del Padre venga a nuestro encuentro en la carne de nuestro Señor, y de su carne reluciente llegue a nosotros, y asi el hombre, rodeado de la luz paterna, adquiera la incorrupción» (Adv. Haer., IV, 20,2). La carne del Salvador ungida-invadida por el Espíritu, caro rutilans, se convierte así en vehículo para ser transmitida a todo el género humano y en todas la edades del hombre.

En el concepto de encarnación del niseno donde brilla la gloria, nos parece ver un sustrato potente del pensamiento del lugdunense. Si bien es cierto que hay diferencias, se pueden encontrar coincidencias a la hora de pensar la acción del Espíritu en la carne en el proceso de divinización. $\mathrm{Y}$ a la hora de establecer los modos de unión el carácter esponsal implícito del obispo de Lyon se hace explícito en el uso de los términos analógicamente que hace el obispo de Nisa. De esa manera lo esponsal no es solo simplemente una metáfora sino una realidad profunda que permite 
explicar la unión de lo divino con lo carnal-corporal. La corona final del Cantar es una figura simbólica y acabada del abrazo nupcial.

\section{La instrumentalidad del cuerpo virginal de María}

Gregorio recurre a la realidad del embarazo inmaculado y el parto sin dolor de la virgen María como un hecho bien significativo:

...la concepción fue inmaculada y el parto no produjo dolor, su tálamo fue la potencia del Altísimo, que como una nube recubre con su sombra la virginidad, la faz nupcial fue la iluminación del Espíritu Santo, el lecho fue la impasibilidad y las bodas fueron la pureza (...) la virgen no sabía cómo fue formado en su cuerpo, el cuerpo que fue receptáculo de Dios (In Cant., XIII, 388).

A partir de este misterio se permite entender cómo el cuerpo se vuelve receptáculo de lo divino, conteniendo al que nada contiene (In Cant., XI, 338). La carne virginal se manifiesta como instrumento. En este lugar el Logos se reviste de la naturaleza humana que es purificada: por la impasibilidad que se vuelve el lecho de la iluminación, que es la acción espiritualizante que la fecunda.

Por su parte, el lugdunense, según la doctrina de la recapitulación que él desarrolla, afirma la conveniencia de tomar carne virgen para la carne del Salvador, el segundo Adán, así como se había tomado de tierra virgen la carne del primer Adán:

El recapituló en sí su antiguo plasma (...) Y así como aquel primer Adán fue plasmado de una tierra no trabajada y aún virgen (...) así, para recapitular a Adán en sí mismo, el mismo Verbo existente recibió justamente de María la que aún era Virgen, el origen de lo que había de recapitular a Adán. Si pues el primer Adán hubiese tenido un hombre como padre y hubiese sido concebido del esperma de varón, justamente se diría que el segundo Adán habría sido engendrado de José. Pero si aquél fue tomado de la tierra, y plasmado por el Verbo de Dios, era conveniente que el mismo Verbo, que había de realizar en sí mismo la recapitulación de Adán, tuviese un origen en todo semejante. Pero entonces, se me dirá, ¿por qué Dios no tomó barro sino realizó de María la criatura que había de nacer? Para que no fuese hecha ninguna otra criatura diversa de aquélla, ni otra criatura que aquella que había de ser salvada, sino la misma que debía ser recapitulada, salvando la semejanza (Adv. Haer., III, 21,10; véase también Epid., 32. 33). 
De esta manera el paralelo de los dos adanes permite descubrir que en la plasis de la carne del Salvador: «ha de mezclarse el Verbo personalmente con la materia, dando lugar a una mixis terrena o corpórea y divina: terrena, por la materia o tierra virginal, ofrecida por María; divina por el Verbo de Dios personalmente unido a la materia» (Orbe, 1969: 88-89).

El principio mariológico al que recurre el lugdunense y el niseno comparte la necesidad del cuerpo virginal como supuesto necesario e instrumental para que establezca una novedosa unión. Entonces se puede descubrir así como la creación de la carne del salvador tiene un carácter especialísimo y lo ubica en la línea de continuidad con la humanidad (Adán).

Gregorio, teniendo este presupuesto de Ireneo, no solamente contempla una unión de lo material con lo espiritual sino que se puede dar un paso más descubriendo una realidad paradójica que permite contener al incontenible.

\section{La Iglesia continente del Espíritu}

En el pensamiento del niseno la corporalidad de la iglesia, la esposa, es ungida enteramente por el perfume de Cristo el esposo, que es el Espíritu de tal manera que poseen el mismo aroma:

Pues, en el Cantar de los Cantares el nardo procura a la esposa el olor del esposo, en cambio en el Evangelio: en todo el mundo y en toda la tierra habitada está la unción del cuerpo entero de la iglesia, el perfume, el cual ha llenado toda la casa; puede encontrarse un ligamen entre estos dos hechos: de modo que entrambos parece una sola cosa (In Cant., III, 93; véase también In Cant., XIII, 392-395; XIV, 400-402).

La realidad novedosa de un cuerpo espiritualizado permite descubrir la capacidad continente y diversificadora de la realidad corporal concreta a la vez que plantea una nueva tensión. Cristo ama a su iglesia como a su cuerpo según el orden del amor. Es posible encontrar en el cuerpo común distintos miembros con funciones y operaciones distintas, incluso aquellos que parece más innobles tiene su importancia. En cada uno de ellos brilla la belleza de la esposa (In Cant., XIV, 420-423). Esto es posible porque el Espíritu de Dios dona su gracia a cada uno según su naturaleza y capacidad de recibir los dones:

Pablo convertido en hijo del Espíritu Santo quedó saturado del aroma perfumante (...) infundía virtud en sus oyentes, aroma fragante de Cristo, (...) 
Cada cual según su capacidad recibía la Palabra de Dios (...) según lo necesitaba cada cual, mezclado con esta copa de libación, aroma perfumante para quienes acogían la Palabra. Así son las mejillas que alaba la esposa cuando describe la hermosura del esposo (In Cant., XIV, 403).

La belleza se da en la diversidad y conformidad de cada una de las partes, por eso no son todos uniformes ni homogéneos. Estos miembros singulares y bellos completan la belleza de la esposa.

La unción es una de las imágenes de contacto que el obispo de Lyon usa para mostrar las relaciones trinitarias: el Padre es el que unge, el Hijo el ungido y el Espíritu la unción misma (Adv. Haer., III, 6, 1; 17, 1; 18, 3; Epid., 9,47). La unción de Cristo por el Espíritu tiene un fin soteriológico (Adv. Haer., III,9,3). Es una unción compartida con todos los miembros del cuerpo eclesial que la han recibido por el bautismo. Se produce una comunicación de la salvación a los hombres a través de la persona del Verbo encarnado, ungido en cuanto hombre y que posee el Espíritu en plenitud. De allí que pueda afirmarse: la salvación como posesión del Espíritu (Gonzalez Faus, 1969: 59-63).

Otra imagen es la de la Iglesia como un vaso portador del Espíritu Santo, que custodia en su interior el «don de Dios» que ha recibido y lo ofrece al exterior sirviendo a la humanidad. Dios puso dentro de este recipiente los ministerios (apóstoles, profetas, doctores) y el resto de las operaciones del Espíritu:

Conservamos esta fe, que hemos recibido de la Iglesia, y siempre por el Espíritu de Dios, como algo precioso que es depositado, mantiene su frescura en un buen vaso y que siempre hace rejuvenecer al mismo vaso en el que está. Por esto es que a la Iglesia ha sido confiado el don de Dios, del mismo modo como el aliento a la plasmación, para esto: para que todos los miembros al haberlo recibido sean vivificados. Y en ella ha sido depositada la comunión con Cristo, esto es el Espíritu Santo, arras de incorruptibilidad, confirmación de nuestra fe y escala de ascensión a Dios. En efecto, dice (Pablo): en la Iglesia, puso Dios apóstoles, profetas, doctores, y toda la restante obra del Espíritu... (Adv. Haer., III, 24,1).

Allí es «donde fueron depositados los carismas de Dios» (Adv. Haer., IV, 26,5). Ellos son «guardados como en una rica bodega de la manera más plena» (Adv. Haer., III, 4,1). Por lo cual se puede afirmar que la Iglesia es para Ireneo un receptáculo pródigo en carismas que manifiestan la actividad del Espíritu de Dios. El Santo Espíritu impregna de sus dones al mismo continente que lo contiene. La Iglesia (continente) se vuelve así espiritual por el Espíritu Santo (contenido) que le transmite las características de su misma vida divina, y así la diviniza. 
La Iglesia como cuerpo de Cristo presupone el concepto cristológico donde lo carnal es invadido y penetrado por lo divino. Luego es comunicado a todos los miembros de Cristo, convirtiéndose (la Cabeza y los miembros) en un continente del Espíritu como un vaso que guarda un valioso líquido en su interior. Gregorio de Nisa al asumir este núcleo conceptual ireneano puede ir más allá aplicando la realidad inherente (unción) del Espíritu Santo en el cuerpo para descubrir la actividad carismática de la iglesia en la diversidad de funciones, articulando la diversidad en la unidad.

\section{Una iglesia samaritana}

Tanto Ireneo (Adv. Haer., III, 17, 3) como Gregorio (In Cant XIV, 426-429) nos aportan una mirada excelente sobre el rol de la Iglesia en medio del mundo. Tanto uno como el otro analizando la parábola del buen samaritano nos permiten descubrir al sujeto eclesial como el lugar donde la humanidad es sanada de las heridas del pecado (Daniélou, 1957: 457-465).

Dice el obispo de Lyon:

El Señor encomendó al Espíritu Santo al hombre que había caído en manos de ladrones y del que se compadeció, vendó sus heridas y le dio dos denarios: para que, recibiendo por el Espíritu la imagen y la inscripción del Padre y del Hijo, hagamos fructificar el denario que se nos ha dado, y lo devolvamos multiplicado al Señor (Adv. Haer. III,17,3).

Para el lugdunense la Iglesia es una morada dónde son acogidos los que por la fe han recibido la acción restauradora del Espíritu de Dios. Cada creyente bajo el influjo del Espíritu completa su curación y se dispone a fructificar para la vida eterna. Por lo tanto la Iglesia es un recinto curativo donde el Espíritu Santo restaura la humanidad herida por el pecado y la prepara para que fructifique en vida eterna (Nicola, 2013: 28). Dice Gregorio de Nisa:

...en aquel que estaba revestido de toda la naturaleza humana por medio de la primicia de la masa, de la cual entra a formar parte todo pueblo: judío, samaritano o griego - en suma todos los hombres- Él con su cuerpo (representado por su cabalgadura), de pie en el lugar de la miseria humana, atendiendo las heridas lo cargó sobre su bestia, lo hizo de tal modo que se volvió posada para el hombre por su amor por la humanidad, en la cual reposan todos los que están cansados y afligidos. Y el que se encuentra en él recibe seguramente en sí mismo a aquel que lo ha encontrado; porque así 
dice el Logos: «permanece en mí y yo en él». Por lo tanto, recibiéndolo (el hombre) en su espacio aloja en sí mismo al ilimitado (In Cant. XIV, 428).

Para el niseno la posada se constituye en un lugar de misericordia donde se cura la miseria humana. El cuerpo del Señor es instrumento terapéutico al asumir a todos los tipos de hombres como primicia de la humanidad entera. Gregorio resalta la dimensión cristológica de intercambio paradójico.

\section{Conclusión}

Al término de nuestro trabajo podemos afirmar que más allá de la demostración material de citas explícitas de San Ireneo en el Comentario al Cantar de los Cantares nos encontramos con núcleos conceptuales, en los cuales están implícitos distintos ideas del lugdunense. Estos son los puntos aglutinadores que subyacen en el pensamiento gregoriano: la economía salvífica: marco teológico y fin soteriológico, la encarnación: el brillo de la gloria en la carne, la instrumentalidad del cuerpo virginal de María, la iglesia continente del Espíritu, una iglesia samaritana.

No podemos realizar un balance material de la recepción ireneana en el texto de Gregorio pero si es notable el peso conceptual que tiene. Aunque no siempre ha sido bien reflejado en los estudios que se han realizo creemos que el Niseno se alista en la ininterrumpida cadena de testigos de la tradición católica que ha resguardado el depósito de la fe a la vez que ha buscado ahondar y profundizar en aquellos principios que los Padres le han legado, en este caso Ireneo. Hay recepción, asunción, reelaboración y progreso en su pensamiento como un aporte a la reflexión patrística de la época.

Queda por descubrir por qué Gregorio no cita directamente al lionés. ¿Cuáles habrán sido las razones para hacerlo? Por ahora no tenemos mayores elementos para intentar responder esta cuestión. Y seguramente pueden aparecer otras resonancias de obispo de Lyon en la lectura del niseno, trabajo que queda abierto para ser enriquecido.

En síntesis: la economía como horizonte permite redescubrir un misterio de bondad que supera toda sospecha de pesimismo que pueda rondar en autores que comentan a Gregorio. La gloria brillando en la carne porque el Espíritu ha abrazo y coronado lo corporal, individual y comunitariamente, permite salir de una concepción negativa de lo carnalcorporal. La instrumentalidad del cuerpo virginal de María colabora en la atención a la novedad paradójica del misterio que permite encontrarse a los contrarios en un lugar común. Una iglesia continente del Espíritu 
sugiere un dinamismo propio que va más allá de las expresiones visibles y permite la integración de lo uno en lo múltiple y la transformación progresiva-salvífica en el proceso de divinización. Una comunidad eclesial con rostro samaritano permite descubrir un lugar concreto para hacer experiencia de la misericordia dentro del plan salvífico de restauración. Todo esto confluye sobre todo como una auténtica historia de amor esponsal, real y abierta a todos los hombres.

\section{REFERENCIAS}

-Bonato, A. (2005). La cognoscenza mistica nelle Omelie sul Catico di Gregorio di Nissa. Teologia, 30 (1), 49-74.

-Bouchet, C. \& Devailly, M. (1992). Grégoire de Nysse. Le Cantique des cantiques. Paris: Migne.

-Brox, N. (1995) Irenäus von Lyon Adversus Haereses. Gegen die Häresien. Freiburg im Breisgau: Herder.

-Canévet, M. (1983). Grégoire de Nysse et l'herméneutique biblique. Etude des rapports entre le langage et la connaisance de Dieu. Paris: Études Augustinennes.

-Curzel, C. (2011). Gli ossimori nelle Omelie sul Cantico dei Cantici e nella Vita de Mosé di Gregorio di Nissa. Augustinianum, 51, (1), 47-83.

-Daniélou, J. (1944). Platonisme et théologie mystique: essai sur la doctrine spirituelle de Saint Grégoire de Nysse. Paris: Aubier.

-Daniélou, J. (1964). Grégoire de Nysse et son milieu: le IV ème siècle. Paris: Instituto Católico.

-Daniélou, J. (1957). Le bon samaritain en Melanges bibliques rédigés en l'bonneur de André Robert. Paris: Bloud et Gay.

-Drobner, H. (2002). Fuentes y métodos filosóficos de Gregorio de Nisa. Teologia y Vida, XLIII, 205-215.

-Dünzl, F. (1994). Gregor von Nyssa, In Canticum canticorum bomiliae. Homilien zum Hohenlied. Freiburg: Herder.

-Fantino, J. (1994). La Théologie d' Irénée. Lecture des Écritures en réponse à l'exégèse gnostique. Un approche trinitaire. Paris: Editions du Cerf.

-Gargano, G. (1981). La teoría di Gregorio di Nissa sul Cantico dei Cantici. Indagine su alcune indicarioni di método esegetico. Roma: Orientalia Christiana Analecta, 216.

-Gonzalez Faus, J. (1969). Carne de Dios. Significado salvador de la Encarnación en la teología de San Ireneo. Barcelona: Herder.

-Gorce, D. (1953). Corps (spiritualité et hygiéne du). En Dictionnaire de spiritualité ascétique et mystique, doctrine et histoire. Paris: Beauchesne.

-Harl, M. (1977). Le langage de l'experience religieuse chez les pères grecs. Rivista di Storia e Letteratura Religiosa, 13, 5-34.

-Langerbeck, H. (1986). Gregorii Nysseni Opera. In Canticum Canticorum. GNO 6. Leiden: E. J. Brill.

-Martín, T. (1993). San Gregorio de Nisa, Comentario al Cantar de los Cantares. Salamanca: Sígueme. 
-Mc Cambley, C. (1987). Saint Gregory of Nissa, Commentary on the Song of songs. Brookline: Mass. Hellenic College Press.

-Moreschini, C. (1996). Gregorio di Nisa, Omelie sul Cantico dei Cantici. Roma: Città Nuova.

-Nicola, A. (2009). La Divinización y el espaciamiento del ser. Gregorio de Nisa leído por Balthasar. Teología y Vida, L, 451-461.

-Nicola, A. (2013). La dimensión pneumatológica de la Iglesia según Ireneo de Lyon. Teología y Vida, LIV, 7- 41.

-Orbe, A. (1985-1988). Teología de San Ireneo. Traducción y comentario del Libro V del "Adversus Haereses". Madrid: B.A.C.

-Orbe, A. (1996). Teología de San Ireneo. Traducción y comentario del Libro IV del “Adversus Haereses". Madrid: B.A.C.

-Orbe, A. (1969). Antropología de San Ireneo. Madrid: B.A.C.

-Polanco, R. (2010). Gloria enim Dei vivens homo, vita autem hominis visio Dei. Reflexiones sobre el homo vivens en el pensamiento de San Ireneo. Santiago de Chile: Anales de la Facultad de Teología.

-Romero Posse, E. (1992). Ireneo de Lión. Demostración de la Predicación Apostólica. Madrid: Ciudad Nueva.

-Rousseau, A. \& Doutreleau, L. (1974/1979/1982). Irénée de Lyon. Contre les Hérésies (Vols. I; II; III). Paris: Du Cerf.

-Rousseau, A., Hemmerdinger, B., Doutreleau, L. \& Mercier, C. (1965/1969). Irénée de Lyon. Contre les Hérésies (Vols. IV; V). Paris: Du Cerf.

-Sagnard, F. (1952). Irénée de Lyon. Contre les Hérésies. Mise en lumière et réfutation de la prétendue "connaissance". Livre III. Paris: Du Cerf.

-Sesboüé, B. (2000). Tout recapituler dans le Christ. Christologie et sotériologie d'Irénée de Lyon. Paris: Desclée.

-Simonetti, M. (1985). L'esegesi dei capadoci. En Lettera e/ o alegoría. Un contributo alla storia dell'esegesi patrística. Roma: Studia Ephemeridis Augustinianun.

-Van Parys, M. (1969). Un colloque sur Grégoire de Nysse. Irénikon, 42, 540545.

Sumario: Introducción; 1. La economía salvífica: marco teológico y fin soteriológico; 2. La encarnación: el brillo de la gloria en la carne, 3. La instrumentalidad del cuerpo virginal de María; 4. La iglesia continente del Espíritu; 5. Una iglesia samaritana; Conclusión; Referencias. 